\title{
Short-Term Forecasting of Nigeria Inflation Rates Using Seasonal ARIMA Model
}

\author{
Ekpenyong Emmanuel John ${ }^{1}$, Udoudo Unyime Patrick ${ }^{2}$ \\ ${ }^{1}$ Department of Statistics, Michael Okpara University of Agriculture, Umudike, Abia State, Nigeria \\ ${ }^{2}$ Department of Statistics, Akwa Ibom State Polytechnic, Ikot Osurua, Akwa Ibom State, Nigeria
}

Email address:

ekpesstat@yahoo.com (E. E. John), udoudogeno@gmail.com (U. U. Patrick)

To cite this article:

Ekpenyong Emmanuel John, Udoudo Unyime Patrick. Short-Term Forecasting of Nigeria Inflation Rates Using Seasonal ARIMA Model. Science Journal of Applied Mathematics and Statistics. Vol. 4, No. 3, 2016, pp. 101-107. doi: 10.11648/j.sjams.20160403.13

Received: March 29, 2016; Accepted: April 29, 2016; Published: May 25, 2016

\begin{abstract}
This paper considers the analyses and forecasting of the monthly All-items (Year-on-Year change) Inflation Rates in Nigeria. The data used for this study are monthly All-items Inflation rates from 2000 to 2015 collected from the Central Bank of Nigeria. Analyses reveal that the Inflation rates of Nigeria are seasonal and follow a seasonal ARIMA Model, (0, 1, 0) $\mathrm{x}(0,1,1)_{12}$. The model is shown to be adequate and the forecast obtained from it are shown to agree closely with the original observations.
\end{abstract}

Keywords: Inflation Rates, Seasonal Time Series, SARIMA Model, Forecasting

\section{Introduction}

Inflation is one of the major economic challenges facing most countries in the world especially African countries with Nigeria not being exception. Inflation is a major focus of economic policy worldwide as described by [5]. Inflation causes global concerns because it can distort economic patterns and can result in the redistribution of wealth when not anticipated. Inflation can also be expressed as a situation where the demand for goods and services exceeds their supply in the economy ([11]). In real terms, inflation means your money can not buy as much as what it could have bought yesterday.

Its importance to the economic growth of a country makes many researchers and economists to apply various time series and econometrics models to forecast or model inflation rates of countries.

[8] in their study in forecasting Nigeria inflation rates used multiplicative seasonal autoregressive integrated moving average (ARIMA) model, $(0,1,1) \times(0,1,1)_{12}$ and fitted the series and made forecast obtained on the basis of the model.

[19] applied SARIMA models in modeling and forecasting Nigeria's inflation rates using Box - Jenkins methodology to build ARIMA model $(1,1,1) \times(0,0,1)_{12}$ and used this model in forecasting Nigeria's rates.
Doguwa and Alade [6] proposed four short term headline inflation forecasting models in Nigeria using the SARIMA and SARIMAX processes and compared their performances using the pseudo-out-of sample forcasting procedure over July, 2011 to September, 2013. Based on the results, they found that the best forecasting performance was demonstrated by the model based on the all-items Consumer Price Index (CPI) estimated using the SARIMAX model. They also added that for forecast of food inflation up to ten months ahead SARIMA was recommended, but for eleven to twelve months ahead the SARIMAX model performed better. However, they concluded that SARIMA model for core inflation consistently outperformed the SARIMAX model and hence should be used for forecasting core inflation.

[1] examined the different types of inflation forecasting models including ARIMA and showed that ARIMA models were modestly successful in explaining inflation dynamics in Nigeria.

Inflation can also discourage investors within and without the country by reducing their confidence level in investments. This is because investors expect high possibility of returns so that they can make good financial decisions. This was in one administration. Due to the change in the administration and the recent economic situation in the country one should embark in this research so as to help policy makers gain 
insights into more appropriate economic and monetary policy in other to combat the predicted rise in inflation rates.

Ojameruaye [16] noted that inflation is usually the result of the interplay of many factors. In most developing countries, including Nigeria, poor and inadequate tax programmes makes government unable to generate enough expenditure, hence the pursuance of the policy of financing the government expenditure by creation of money inevitable ([18]). The structuralists explain the long-run inflationary trend in developing countries in terms of structural rigidities, market imperfection and social tension, relative inelasticity of food supply, foreign exchange constraint protective measures, rise in demand for food, fall in export earnings, hoarding import substation, industrialization, political instabilities ([18]).

Monetarists opine that "inflation is always and everywhere", hence prices tend to rise when the rate of inflation in money supply is greater than the rate of increase in real output of goods and services ([13]).

Imimole and Enoma [12] conducted a research on the impact of exchange rate depreciation on inflation in Nigeria using auto regression distributed lag (ARDL) and co integration procedures. Evidence from the estimate results suggested that exchange rate depreciation, money supply and real gross domestic product were the main determinants of inflation in Nigeria.

[20] in their study of modeling the Nigeria inflation rates using Periodogram and Fourier series analysis from 2003 to 2011 showed that inflation rates was periodic in nature. They further added that the periodicity of the inflation rates was a function of different government administration. They finally used the model to make some forecast, which they showed to be adequate. [15] critically examined the dynamic and simultaneous inter-relationship between inflation and its determinants in Nigeria within the period 1970 - 2007. The Augumented Engle - Granger (AEG), cointegration test and error correction model were employed. The estimated result indicated that substantial benefits occurred when moving from high or moderate rate to low level of inflation.

[10] used an error correction model to determine the factors that affect inflation in Nigeria. The result indicated that monetary expansion, driven mainly by fiscal policies, explains to a large degree the inflationary process in Nigeria.

[9] studied inflation in Nigeria using autoregressive distributed lag (ARDL) model. He found that inflation is dependent on the growth of broad money, exchange rate of the naira vis-a-vis the dollar, the growth of real income, the level of rainfall, and the level of anticipated inflation, which was based on the previous year's level of inflation.

[4] propose an entire family of models, called autoregressive integrated moving average (ARIMA) models. ARIMA models are especially suited for short term forecasting. This is because the model places more emphasis on the recent past rather than distant past. This emphasis on the recent past means that long-term forecasts from ARIMA models are less reliable than short-term forecasts. Seasonal
Autoregressive Integrated Moving Average (SARIMA) model is an extension of the ordinary ARIMA model to analyze time series data which contain seasonal and nonseasonal behavoiurs.

SARIMA model accounts for the seasonal property in the time series. The forecasting advantage of SARIMA model compared to other time series models have been investigated by many studies. For example, [2] used SARIMA model to forecast Irish inflation, [14] applied SARIMA model approach in other to forecast Irish inflation, and [21] applied SARIMA model to forecast short term inflation in Croatia. [23] applied SARIMA model and Hot-winters exponential smoothing approach to forecast container transshipment in Germany, according to their result, SARIMA approach yield slightly better values of modeling the container through put than the exponential smoothing approach.

A reason why simple time series models tend to outperforms their theoretical counter parts lies in the restrictive nature of econometric models with their improper restriction and specification on structural variables. The absence of restriction in the ARIMA model gives it the necessary flexibility to capture dynamic properties and thus significant advantage in short run forecasting ([21]). Encouraged by these empirical results on the superiority of ARIMA models, [21] applied seasonal Autoregressive integrated moving Average (SARIMA) model to forecast the Turkish inflation.

Having known the advantage of SARIMA for accurate forecasting over short periods, we seek to use the model in modeling the current inflation rate in Nigeria for the recent periods, which other works on Inflation could not capture, and also to make good forecast of it.

\section{Materials and Methods}

The data for this study are Nigeria monthly All-items Inflation Rates (Year on Change) from January, 2000 to June, 2015 obtained from the Data and Statistics Publications of the Central Bank of Nigeria $(\mathrm{CBN})$ retrievable from the website http://www.cenbank.org.

\subsection{Seasonal ARIMA Models}

A time series is said to be seasonal of order $d$ if there exists a tendency for the series to exhibit periodic behaviour at regular or almost regular time interval $\mathrm{d}$.

The time series $\left\{X_{t}\right\}$ is said to have a multiplicative ( $\left.p, d, q\right)$ $\mathrm{x}(\mathrm{P}, \mathrm{D}, \mathrm{Q})_{\mathrm{s}}$ seasonal ARIMA model if:

$$
A(B) \Phi\left(B^{s}\right) \nabla^{d} \nabla_{s}^{D} X_{t}=\mathrm{B}(B) \Theta\left(B^{s}\right) \varepsilon_{t}
$$

where $\Phi$ and $\Theta$ are polynomials of order P and Q respectively. That is

$$
\begin{aligned}
& \Phi\left(B^{s}\right)=1+\phi_{1} B^{s}+\cdots+\phi_{p} B^{s p} \\
& \Theta\left(B^{s}\right)=1+\theta_{1} B^{s}+\cdots+\theta_{p} B^{s p}
\end{aligned}
$$

where $\phi_{j}$ and $\theta_{j}$ are constants such that the zeros of 
equations (2) and (3) are all outside the unit circle for stationarity and invertibility conditions respectively. Equations (2) and (3) represent the Autoregressive (AR) and Moving Average (MA) operators respectively.

\subsection{Determination of the Orders of SARIMA Models (d, D, $p, P, q$ and $Q$ )}

Existence of a seasonal nature in a series is often evident from the time plot. Moreover, for a seasonal series, the Autocorrelation Function (ACF) exhibits a spike at the seasonal lag. Seasonal differencing is necessary to remove the seasonal trend. If there exists a secular trend, then nonseasonal differencing is necessary. Etuk [8] stated that to avoid undue model complexity, orders of differencing $d$ and $\mathrm{D}$ should add up to at most $2($ i.e $\mathrm{d}+\mathrm{D}<3$ ). If the ACF of the differenced has a positive spike at the seasonal lag, then a seasonal AR component is suggestive; but if it has a negative spike, then a seasonal MA term is suggestive.

As it is already known, an AR (p) model has a Partial Autocorrelation function (PACF) that truncates at lag $p$ and an MA (q) has an ACF that truncates at lag q. In practice, $\pm 2 / \sqrt{n}$, where $n$ is the sample size, are the confidence limits for both functions.

\subsection{Model Estimation}

The involvement of the white noise terms in an ARIMA model entails a non-linear iterative process in the estimation of the parameters. An optimization criterion like least error of sum of squares, maximum likelihood or maximum entropy is used. An initial estimate is usually used. Each Iteration is expected to be an improvement of the last one until the estimate converges to an optimal one. However, for pure AR and MA models, linear optimization techniques exist. MINITAB Package would be used for the estimation of the parameters of the model.

\subsection{Diagnostic Checking}

The model that is fitted to the data is tested for adequacy through some analysis of the properties of residuals of the model. If the model is adequate, the residuals would be uncorrelated and would be normally distributed with zero mean and constant variance. Also, the ACF of the residuals should not be significantly different from zero.

\subsection{Forecasting}

The estimated model would be used to make forecast for future values. In assessing the adequacy of the forecasts, Theil Inequality Coefficient is used. The Theil Coefficient is given as:

$$
U=\sqrt{\sum_{i=1}^{n}\left(X_{t}-\hat{X}_{t}\right)^{2} / n} / \sqrt{\sum_{i=1}^{n} X_{t}^{2} / n}+\sqrt{\sum_{i=1}^{n} \hat{X}_{t}^{2} / n}
$$

where $X_{t}$ and $\hat{X}_{t}$ are the actual and estimated Inflation rates respectively, $\mathrm{n}$ is the number of observations. The closer the value of $U$ is to zero, the better the forecasts.

\section{Results}

A clear assessment of the plot of the original series in Fig. 1 shows the existence of trend, cyclical and seasonal variations, which indicates that the series is non-stationary. Seasonal differencing of the series produces a series $S D X_{t}$ in Fig. 2 with no trend nor clear seasonality. Non-seasonal differencing yields a series $N D S X_{t}$ with no significant trend and no clear seasonality (see fig. 3 ).

The ACF of the differenced series in figure 4 shows a negative spike at lag 12 , revealing a seasonal MA component of order one. The PACF in figure 5 indicates no spike in the early lags suggesting no non-seasonal MA or AR component. Therefore, the proposed multiplicative model is SARIMA ( 0 , $1,0) \times(0,1,1)_{12}$.

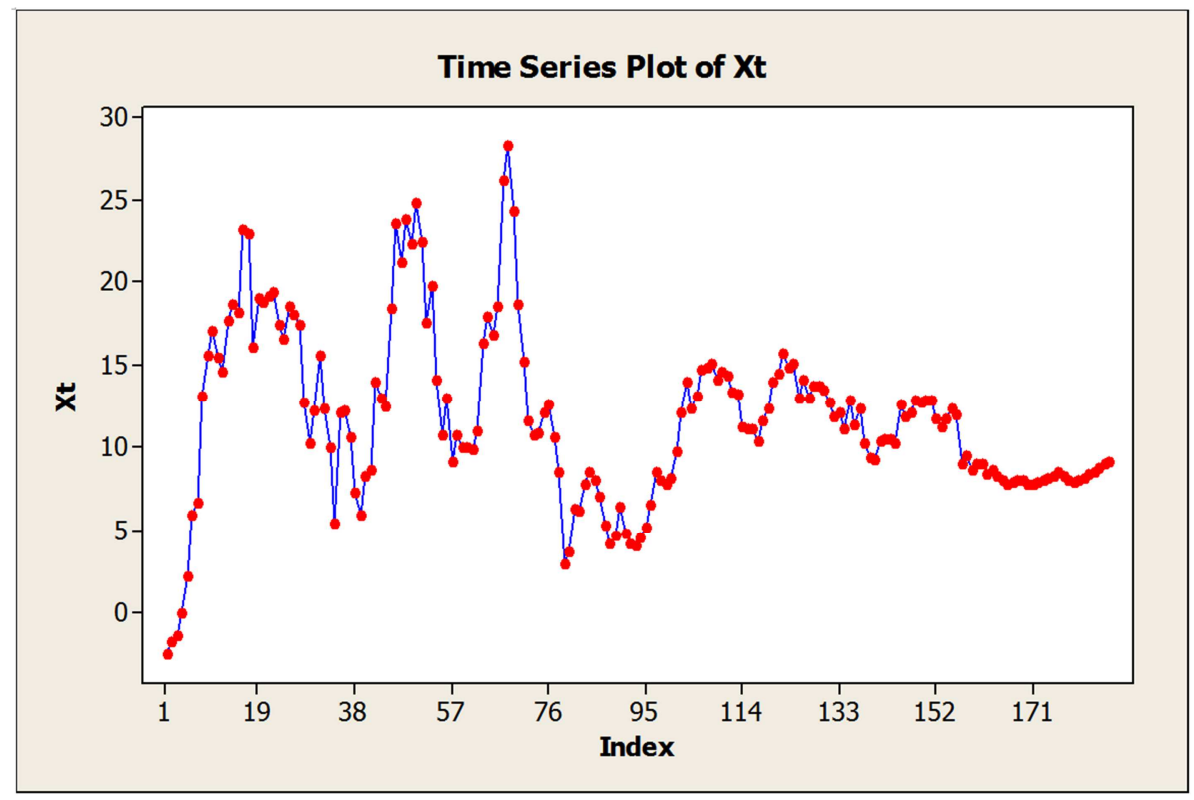

Fig. 1. Time plot of the Original Inflation Rates. 


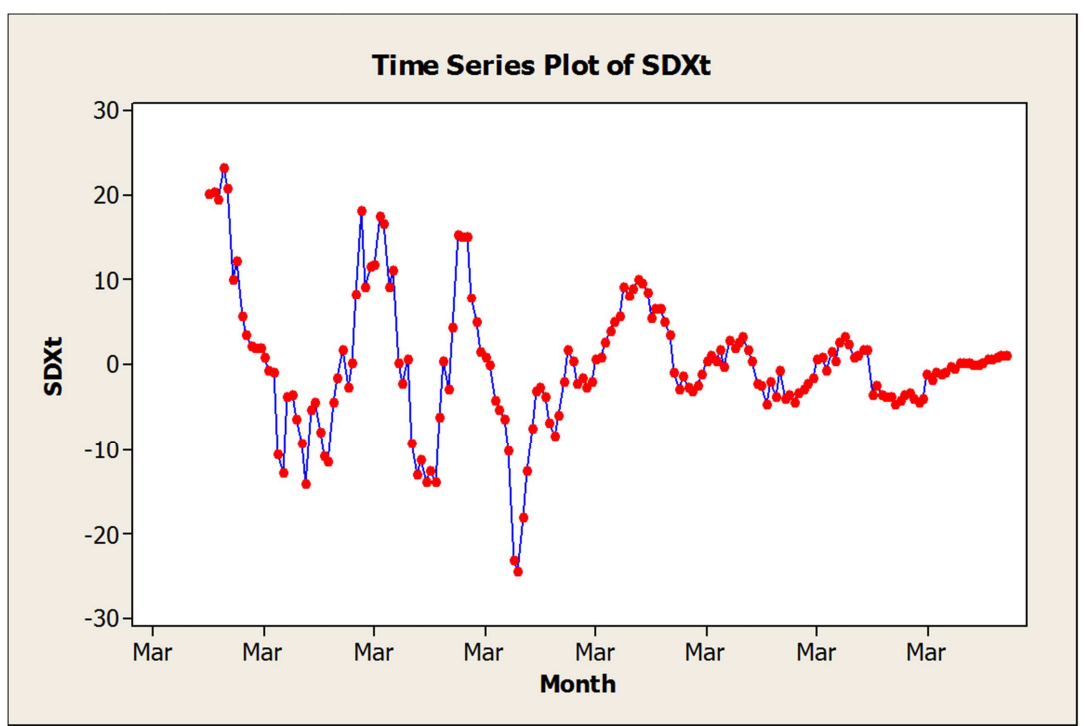

Fig. 2. Plot of Seasonally differenced series.

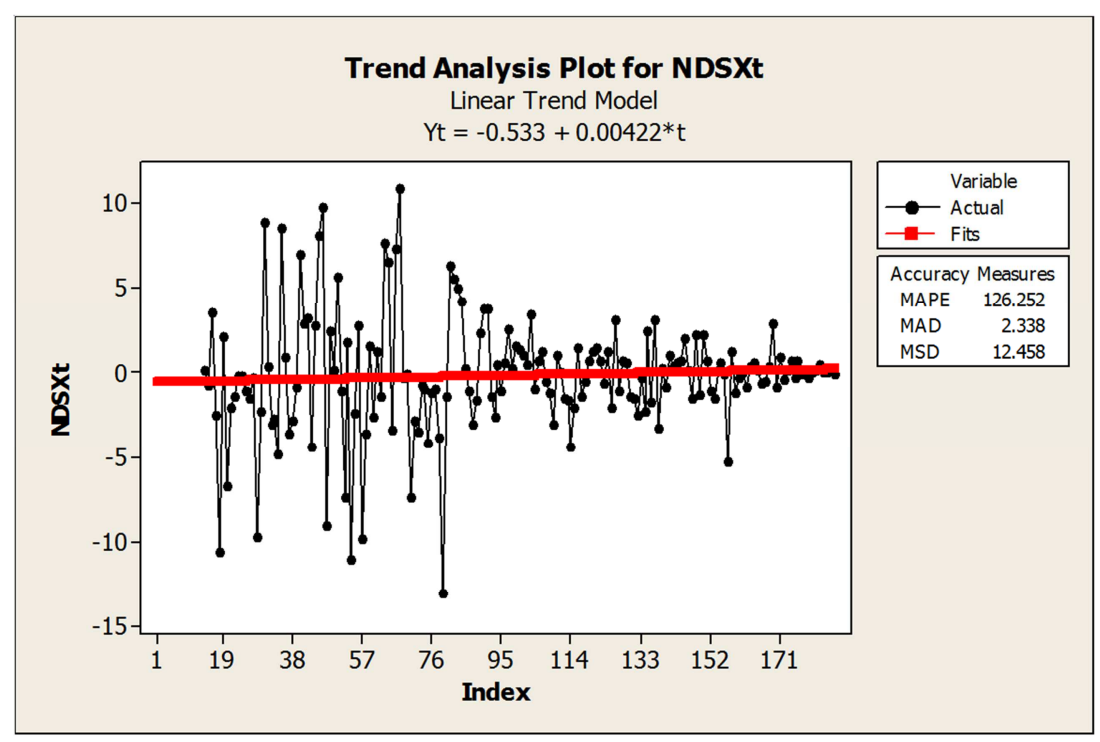

Fig. 3. Plot of Non-seasonally differenced series with trend analysis.

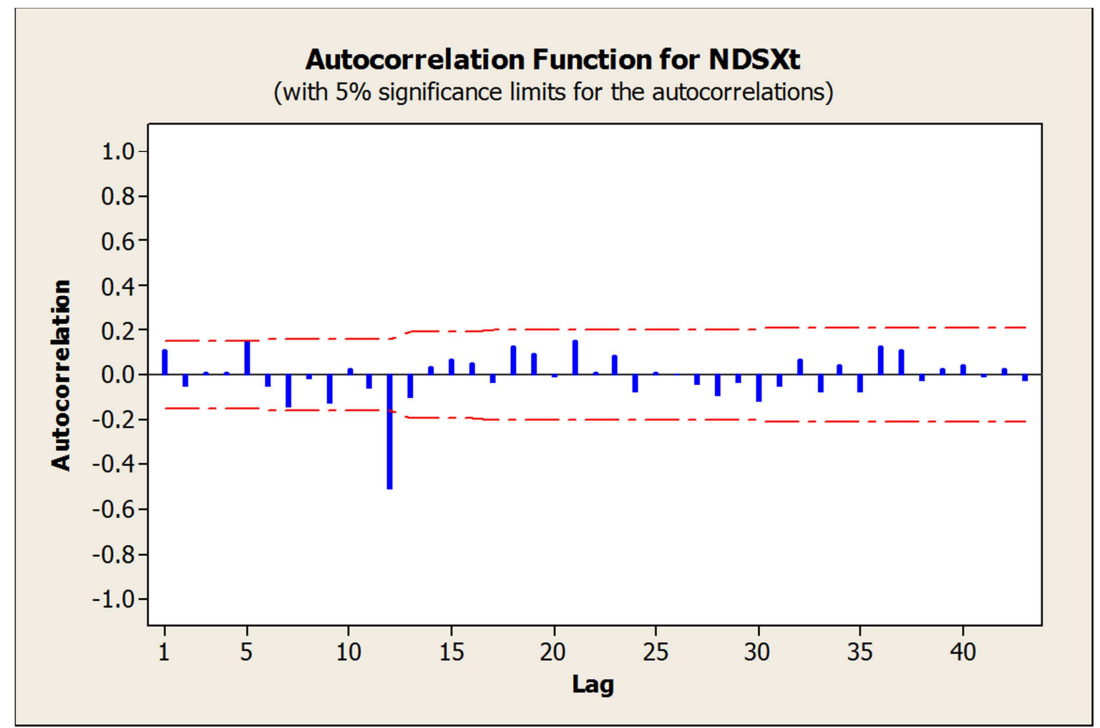

Fig. 4. ACF of NDSXt. 


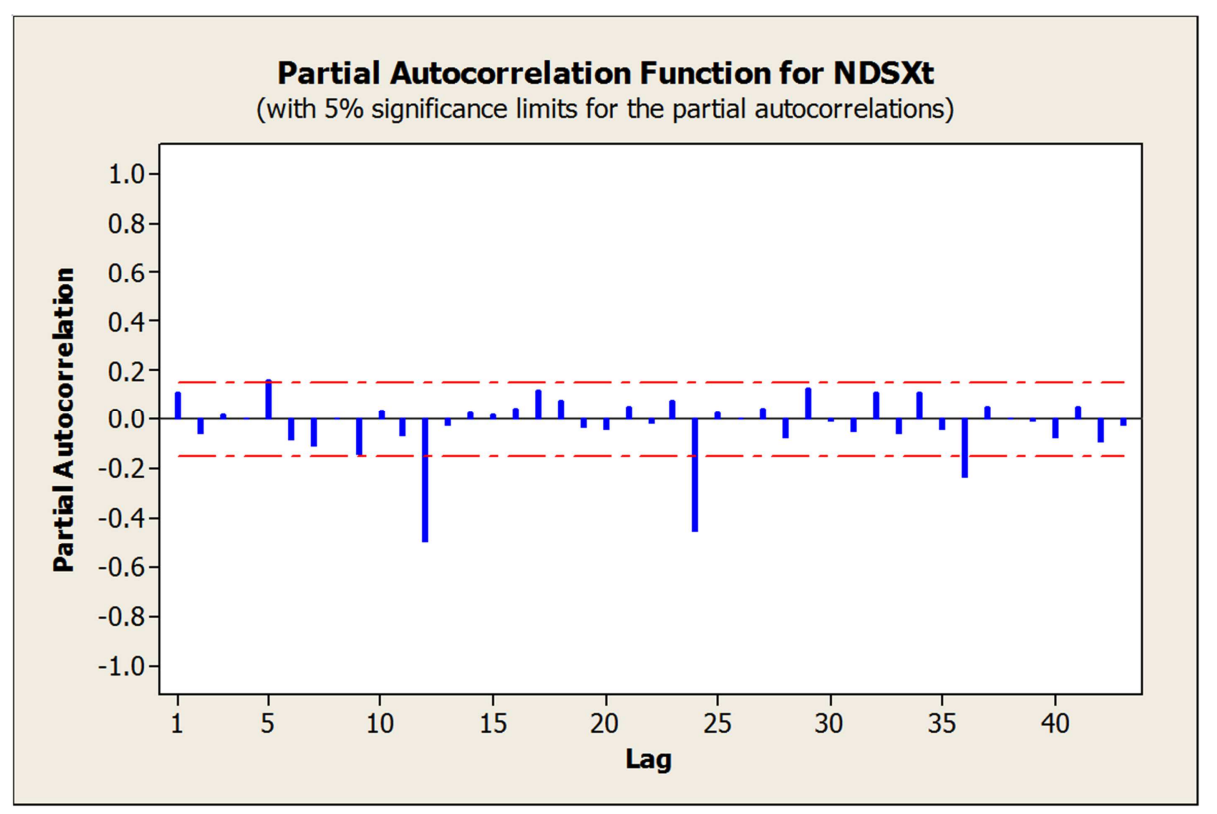

Fig. 5. PACF of NDSXt.

\subsection{Estimation of Parameters}

The MINITAB results for estimating the parameters of the proposed model is given in Table 1 .

Table 1. Final Estimates of Parameters.

\begin{tabular}{llllll}
\hline Type & & Coef & SE Coef & T & P \\
\hline SMA & 12 & 1.0068 & 0.0377 & 26.69 & 0.00 \\
\hline
\end{tabular}

Differencing: 1 regular, 1 seasonal of order 12.

Number of observations: Original series 186, after differencing 173

Residuals: $\mathrm{SS}=774.226$ (backforecasts excluded)

$\mathrm{MS}=4.501 \mathrm{DF}=172$

The estimated model is therefore given as:

$$
\hat{X}_{t}=X_{t-1}+X_{t-12}-X_{t-13}-e_{t-12}
$$

The plot of the Actual and Estimated Inflation Rates are shown in fig. 6 and it shows that the model fits well to the data.

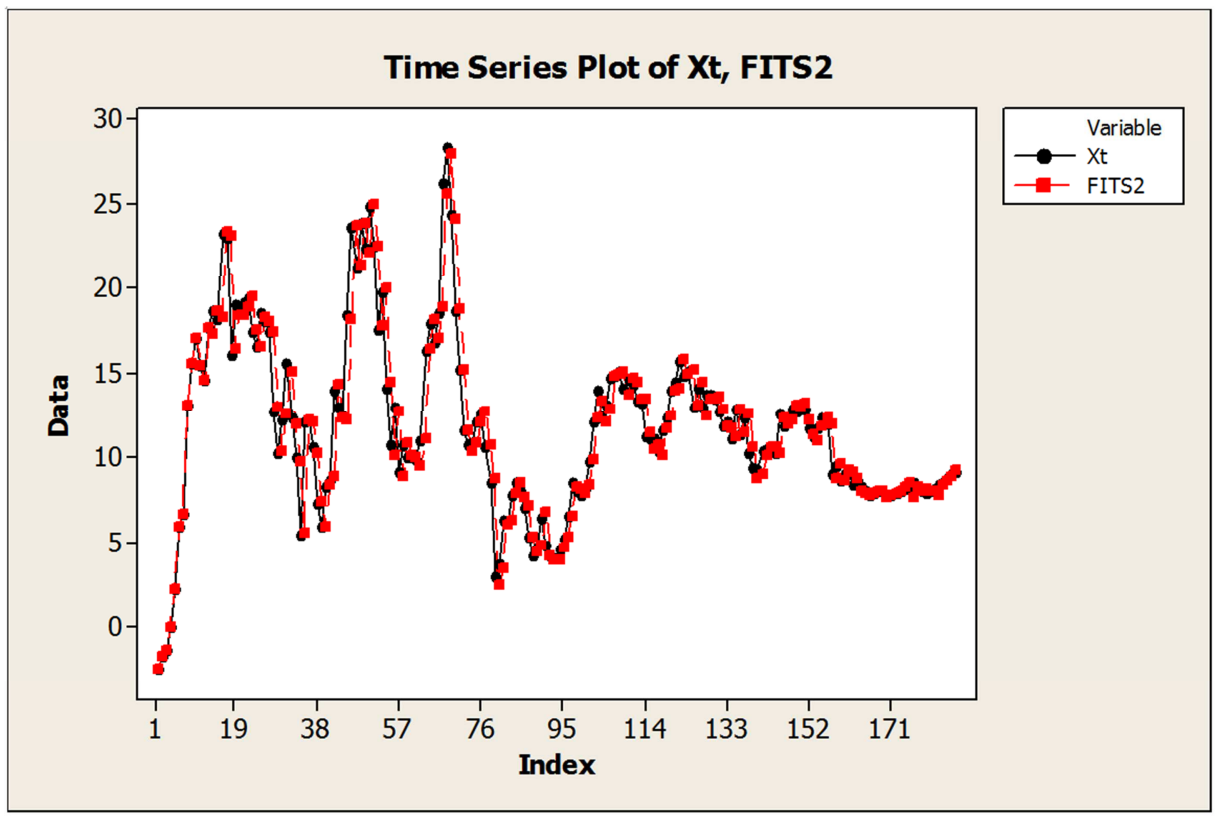

Fig. 6. Plot of Actual and Estimated Series.

\subsection{Diagnostic Checking}

The ACF of the Residuals indicates that two out of 186 falls outside the confidence region, as shown in fig. 7, thereby confirming the adequacy of the model. 


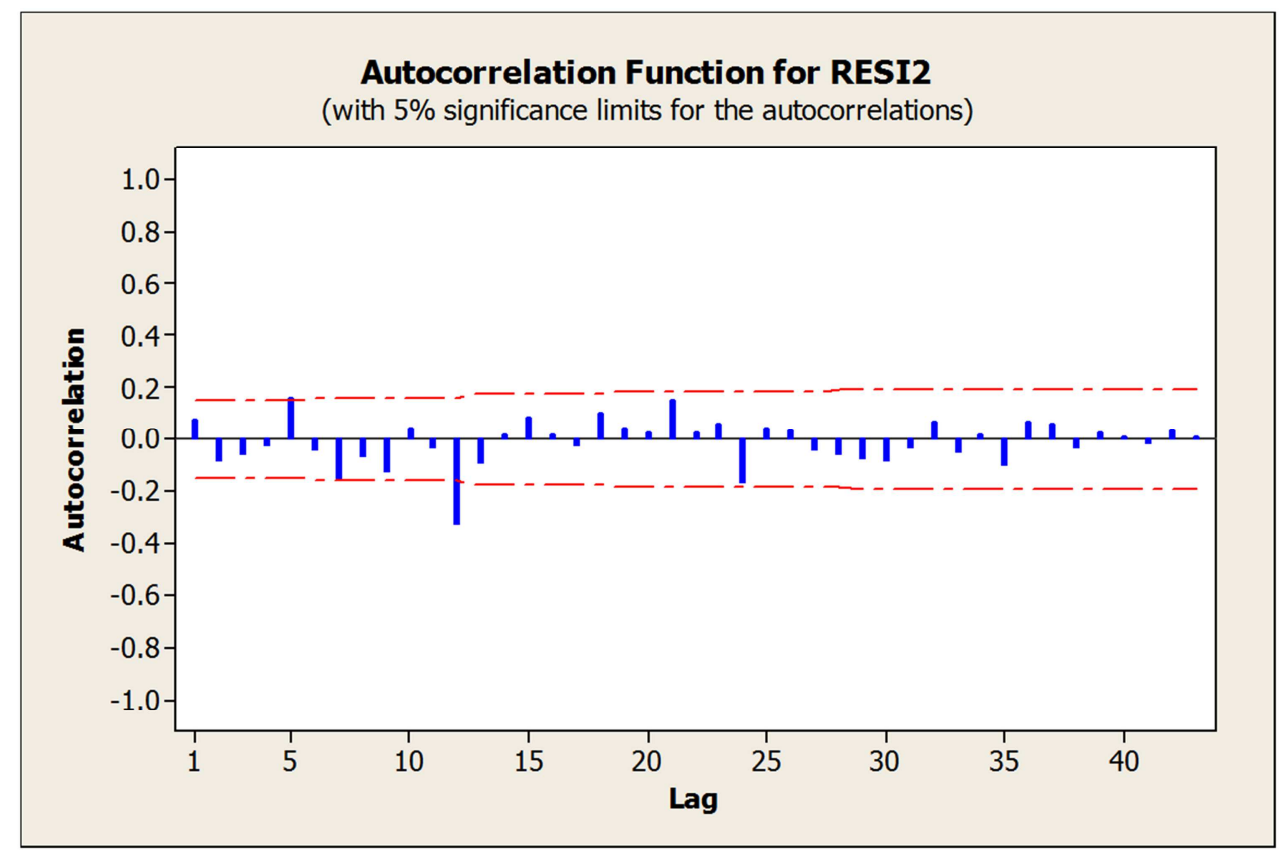

Fig. 7. ACF of Residuals.

\subsection{Forcasting of the Future Inflation Rates}

The 12-month forecasts of the Nigeria Inflation rates using equation (6) are given in Table 2 below:

Table 2. Forecasts for the Inflation Rates.

\begin{tabular}{lllll}
\hline \multirow{2}{*}{ Period } & \multirow{2}{*}{ Forecast } & \multicolumn{2}{c}{$\mathbf{9 5 \%}$ confidence Limits } & \multirow{2}{*}{ Actual } \\
\cline { 3 - 4 } & & Lower & Upper & \\
\hline July, 2015 & 9.5233 & 5.3641 & 13.6826 & 9.22 \\
August, 2015 & 8.9097 & 3.0276 & 14.7917 & 9.34 \\
September, 2015 & 8.6104 & 1.4064 & 15.8144 & 9.40 \\
October, 2015 & 8.3426 & 0.0241 & 16.6610 & 9.30 \\
November, 2015 & 8.4672 & -0.8331 & 17.7675 & 9.37 \\
December, 2015 & 8.5447 & -1.6433 & 18.7327 & 9.55 \\
January, 2016 & 8.5437 & -2.4616 & 19.5470 & 9.60 \\
\hline
\end{tabular}

In assessing the adequacy of the forecasts, Theil Inequality Coefficient is calculated as:

$$
\begin{gathered}
\sum_{i=1}^{n}\left(X_{t}-\hat{X}_{t}\right)^{2} / n=0.67981, \sum_{i=1}^{n} X_{t}^{2} / n 88.3219, \sum_{i=1}^{n} \hat{X}_{t}^{2} / n=75.9306 \\
U=\sqrt{0.6798} /(\sqrt{88.3219}+\sqrt{75.9306})=0.04
\end{gathered}
$$

Since $U=0.04$ is very close to zero, then the model can favourably be used to forecast the future values of Inflation rates.

\section{Discussion}

It is observed that authors that modeled Inflation Rates have different models that can be used to forecast monthly inflation rates. Etuk [7] have shown that a multiplicative seasonal ARIMA model, $(1,1,0) \times(0,1,1)_{12}$ was adequate for modeling Inflation rates from 2003 to 2011. Also, [8] modeled the same Inflation rates within the same period using SARIMA $(0,1,1) \times(0,1,1)$, but did not show the forecast adequacy. Further, [19] applied seasonal multiplicative ARIMA model, SARIMA $(1,1,1) \times(0,0,1)_{12}$ to model Nigeria Inflation rates from November, 2003 to October 2013. Others made use of Consumer Price Index to model Inflation rates. These authors include [17], [6], etc. The significant feature in all these works is that Nigeria Inflation Rates are seasonal in nature. On the other hand, it has been observed that models fitted to the Inflation rates are different. This is due to the period under consideration and the type of Inflation data used. This confirms [6] assertion that ARIMA model was suitable for forcasting core inflation, while shorter term forecasting was favoured by SARIMA models. In this study the period under consideration has covered 2014 and part of 2015 which other works did not include. This definitely affects the type of model, since it is a model for short term forecasts.

\section{Conclusion}

The monthly All-items Inflation rates of Nigeria have been shown to follow a seasonal ARIMA. $(0,1,0) \times(0,1,1)$ and this model has been shown to be adequate. Also, the model has been used to make forecasts for future values, which has been found to be appropriate.

\section{References}

[1] Adebiyi, M. A., Adenuga, A. O., Abeng, M. O., Omanukwe, P. N., and Ononugbo, M. C. (2010): Inflation forecasting models for Nigeria. Central Bank of Nigeria Occassional Paper No. 36, Abuja, Research and Statistics Department.

[2] Aidan, M., Geoff, K. and Terry, Q. (1998): Forecasting Irish Inflation using ARIMA Models. CBI Technical Papers 3/RT/98: 1-48. Central Bank and Financial Services Authority of Ireland. 
[3] Alan, P. (1983): Forecasting with univariate Box and Jenkins Models: Concepts and Case. Wiley and Sons. New York.

[4] Box, G. E. P. and Jenkins, G. M. (1976): Time series Analysis, Forecasting and Control. Holden Day, San Francisco.

[5] David, F. H. (2001): Modeling UK Inflation (1875 - 1991). Journal of Applied Econometrics, 16 (3), 255-275.

[6] Doguwa, S. I. and Alade, S. O. (2013): Short-term Inflation Forecasting Models for Nigeria. CBN Journal of Applied Statistics, 4 (2), 1-29.

[7] Etuk, E. H. (2012): Predicting Inflation Rates of Nigeria Using a Seasonal Box-Jenkins Model. Journal of Statistical and Econometric Methods, 1 (3), 27-37.

[8] Etuk, E. H., Uchendu, B. and Victoredema, U. A. (2012): Forecasting Nigeria Inflation Rates by a Seasonal ARIMA Model. Canadian Journal of Pure and Applied Sciences, 6 (3), 2179-2185.

[9] Fakiyesi, O. M. (1996): Further Empirical Analysis of Inflation in Nigeria. Central Bank of Nigeria Economic and Financial Review, 34 (1), 489-499.

[10] Gary, G. M. (1995): The main determinants of Inflation in Nigeria. IMF Staff Papers. International Monetary Fund, 42 (2), 270-289.

[11] Hall, R. (1982): Inflation: Causes and Effects. University of Chicago Press, Chicago.

[12] Imimole, B. and Enoma, A. (2011): Exchange Rates Depreciation and Inflation in Nigeria (1986-2008). Business and Economics Journal, BEJ-28, 1-12.

[13] Johnson, H. G. (1973): Further Essay in Monetary Economy. George Wallen and Unwin. London.

[14] Junttila, J. (2001): Structural breaks, ARIMA models and finish Inflation forecasts. International Journal of Forecasting, 17, 203-230.

[15] Odusanya, I. A. and Atanda, A. A. M. (2010): Analysis of Inflation and its determinants in Nigeria: Pakistan Journal of Social Sciences, 7 (2), 97-100.

[16] Ojameruaye, E. O. (1998): Analysis of the determinants of general price level in Nigeria. Research and Development, 5 $(1,2), 80-96$.

[17] Olajide, J. T., Ayansola, O. A., Odusina, M. T. and Oyenuga, I. F. (2012): Forecasting the Inflation Rates in Nigeria: BoxJenkins Approach. IOSR Journal of Mathematics, 3 (5), 15-19.

[18] Onwioduokit, E. A. (2002): Fiscal Deficit and Inflation in Nigeria: An Empirical Investigation of Causal Relationships. $C B N$ Economic and Financial Review, 37 (2), 1-1.

[19] Otu, A. O., Osuji, G. A., Opara, J., Mbachu, H. I. and Iheagwara, A. I. (2014): Application of SARIMA models in modeling and forecasting Nigeria's Inflation Rates. American Journal of Applied Mathematics and Statistics, 2 (1), 16-28.

[20] Omekara, C. O., Ekpenyong, E. J. and Ekerete, M. P. (2013): Modeling the Nigeria Inflation Rates using Periodogram and Fourier Series Analysis. CBN Journal of Applied Statistics, 4 (2), 51-68.

[21] Pufnik, A. and Kunovac, D. (2006): Short-term Forecasting of Inflation in Croatia with Seasonal ARIMA processes. Working Paper, w-16, Croatia National Bank.

[22] Saz, G. (2011): The Efficacy of SARIMA Models for Forecasting Inflation Rates of Developing Countries: The Case for Turkey. International Research Journal and Finance and Economics, 62, 111-142.

[23] Schulz, P. M. and Prinz, A. (2009): Forecasting Container Transhipment in Germany. Applied Economics, 41 (22), 28092815. 